\title{
Invasão viking na atual historiografia brasileira
}

\author{
Leandro Vilar Oliveira ${ }^{674}$
}

\section{Resenha}

LANGER, Johnni; AYOUB, Munir Lufte (Orgs.). Desvendando os vikings. um estudo de cultura nórdica medieval. João Pessoa: Ideia, 2016.

Vikings é um tema que atualmente no Brasil encontra-se em bastante evidência, principalmente devido a influências da cultura pop com seriados, filmes, jogos e livros de ficção, no entanto, o estudo sobre esses povos vem ocorrendo mais regularmente no país nos últimos dez anos ${ }^{675}$. No entanto, a disponibilidade de obras em língua portuguesa sobre esse tema ainda é escassa e isso dificulta os interessados na área em poder se aprofundar a respeito, pois aqueles que não possuem domínio de outras línguas acabam por encontrar dificuldades de acessar fontes, materiais, discussões etc., que não existem em língua portuguesa.

No caso do Brasil, possuímos alguns poucos livros sobre história viking, a começar pelo importante trabalho do arqueólogo Holger Arbman, intitulado The Vikings ${ }^{676}$, que foi traduzido em Portugal em 1967, fazendo parte da coleção História Mundi. O livro apresenta um panorama geral da Era Viking (VIII-XI) e fornece dados interessantes sobre a cultura material, além de trazer mapas e imagens. Porém, outro livro sobre a temática, só seria lançado no Brasil, treze anos depois, intitulado Os Vikings (1980) de Johannes Brondested ${ }^{677}$. Obra publicada originalmente década de 1950, que chegou tardiamente ao país, e já

\footnotetext{
${ }^{674}$ Doutorando em Ciências das Religiões (UFPB), Mestre em História e Cultura Histórica (UFPB), membro pesquisador do Núcleo de Estudos Vikings e Escandinavos (NEVE), membro pesquisador do VIVARIUM-NE (Laboratório de estudos da Antiguidade e do Medievo).

675 LANGER, Johnni. Uma breve historiografia dos estudos brasileiros de religião nórdica medieval. Horizonte, Belo Horizonte, v. 14, n. 43, jul./set. 2016, p. 919-923.

${ }^{676}$ ARBMAN, Holger. Os Vikings. Lisboa: Editorial Verbo, 1967. (Coleção História Mundi, v. 8).

677 BRONDSTED, Johannes. Os vikings. São Paulo: Hemus, 1980
} 
desatualizada. Em 1988 foi publicado Os vikings: reis dos mares de autoria de Yves Cohet ${ }^{678}$, outra obra traduzida.

Na década de 1990 tivemos a publicação de dois livros, ambos também eram traduções. As invasões normandas (1997) de Albert Haenens ${ }^{679}$, obra que focava a colonização viking da Normandia, região no noroeste da França; Os viquingues (1997) de James GrahamCampbell ${ }^{680}$, livro que apresentava de forma geral a história dos vikings, tendo sido publicado em dois volumes. A obra foi republicada para o Brasil em volume único, em formato maior e ricamente ilustrado em $2006^{681}$.

Excetuando-se os livros publicados na década de 1990, os anteriores estão bem desatualizados em termos metodológicos, teóricos e até mesmo informativos, pois novas descobertas arqueológicas foram realizadas no final do século XX. Nesse sentido, obras mais recentes já fazem referência a algumas destas novidades.

Em 2009 foi publicado o livro Escandinávia ${ }^{682}$, ricamente ilustrado, mas com conteúdo didático acerca do tema. Todas as obras sobre os nórdicos até então publicadas no Brasil consistiam em traduções, mas no final dos anos 2000, começou a ser publicados trabalhos de origem brasileira. O livro Deuses, monstros, heróis - ensaios de mitologia e religião viking (2009) de Johnni Langer ${ }^{683}$, em 2011 foi publicado Poder e Sociedade na Noruega Medieval de Pablo Gomes de Miranda ${ }^{684}$, e no ano seguinte tivemos Escandinávia medieval (2012), obra organizada por Renan Birro e Johnni Langer ${ }^{685}$. Estes três livros mencionados anteriormente consistem em produções originais em língua portuguesa e publicadas por estudiosos brasileiros, já apresentando conteúdo atualizado acerca da temática.

Sendo assim, o livro Desvendando os vikings, obra organizada pelo prof. Dr. Johnni Langer (UFPB/NEVE/VIVARIUM-NE) ao lado do Me. Munir Lefte Ayoub (USP/NEVE) faz parte do atual cenário em que os estudos vikings e escandinavos estão em alta no país. Nos últimos dois anos, três livros foram publicados, sendo que os outros dois: Na trilha dos vikings ${ }^{686}$

\footnotetext{
${ }^{678}$ COHAT, Yves. Os vikings: reis dos mares. São Paulo: Círculo de Leitores, 1988.

679 HAENENS, Albert. As invasões normandas: uma catástrofe? São Paulo: Perspectiva, 1997.

${ }^{680}$ GRAHAM-CAMPBELL, James. Os viquingues. São Paulo: Del Prado, 1997. 2v.

${ }^{681}$ GRAHAM-CAMPBELL, James. Os vikings. Barcelona: Editora Folio S.A. 2006.

682 ESCANDINÁVIA: terra dos guerreiros e navegantes. São Paulo: Folio, 2009.

${ }^{683}$ LANGER, Johnni. Deuses, monstros, heróis - ensaios de mitologia viking. Brasília: Editora da UnB, 2009.

${ }^{684}$ MIRANDA, Pablo Gomes de. Poder e Sociedade na Noruega medieval. São Paulo: AGbook, 2011.

685 BIRRO, Renan M; LANGER, Johnni (orgs). Escandinávia medieval. Vitória: DLL/UFES, 2012.

${ }^{686}$ LANGER, Johnni. Na trilha dos vikings: estudos de religiosidade nórdica. João Pessoa: Editora da UFPB, 2015.
} 
(2015) e Fé nórdica ${ }^{687}$ (2015) consistem em obras de temática específica, abordando o caráter religioso e mitológico, por sua vez o livro Desvendando os vikings nos apresenta um panorama mais amplo e diverso de assuntos.

O livro é dividido em 12 capítulos, escritos por doutores, doutorandos, mestres e mestrandos, os quais possuem trabalhos na área escandinava ou viking. Cada capítulo procurou abordar de forma básica questões no âmbito cultural e social, referindo-se a linguagem, linguística, as artes, a religião, crenças e mitos. Os capítulos que compõem a obra são: Paleografia, Linguagem, Oralidade e Performance, Literatura, Arte, Religião e Marcialidade, Funerais e Crenças, Arqueologia, Cosmologia, Mitologia, Magia e Poesia.

Os quatro primeiros capítulos são bastante interessantes por abordarem o nórdico antigo, a língua falada pelos vikings, como também traz fontes e referências medievais sobre tais povos. O fato dos nórdicos terem viajado por vários locais da Europa, Oriente Médio e até mesmo chegaram à América do Norte, contribuiu para a difusão da sua língua, embora que em muitos lugares ela pouco influenciou os idiomas locais, mas no caso da Inglaterra, da Normandia, da Irlanda, Islândia e Groenlândia, várias palavras em língua inglesa e irlandesa, são de origem escandinava. Além do fato de que na toponímia destes lugares, nomes escandinavos ainda figuram na geografia atual.

Entretanto, por mais que os nórdicos tenham possuído um idioma próprio com suas variedades regionais e até mesmo uma escrita, o alfabeto rúnico, todavia, eles não deixaram documentação escrita nesse alfabeto, exceto algumas breves inscrições em objetos e nas pedras rúnicas (runestones). Muitas das obras que narram a história e mitologia dos vikings datam de épocas posteriores e foram redigidas com o alfabeto latino, sendo escritas em latim, islandês, norueguês, sueco, dinamarquês, inglês, alemão etc.

Este aspecto facilita o acesso a essa documentação que desde a Idade Moderna vem sendo traduzida e atualizada para as atuais normas ortográficas de cada língua. Nos capítulos Paleografia e Literatura de autoria de Rodrigo Moura e Luciana de Campos foram apresentadas algumas dessas fontes, dissertando a respeito de suas origens, tipologias, conteúdos e importância para o estudo de diferentes temáticas da Era Viking e até mesmo dos períodos posteriores, pois lugares como a Islândia, entre os séculos XI e XIV, consistiu em um polo intelectual, tendo produzido uma vasta documentação sobre o país e sua história. Tal

${ }^{687}$ LANGER, Johnni. Fé nórdica: mito e religião na Escandinávia medieval. João Pessoa: Editora da UFPB, 2015. 
condição é visível quando se pensa que as principais referências escritas sobre a mitologia nórdica que são a Edda Poética (XIII) e a Edda em Prosa (XIII), foram escritas na Islândia.

O capítulo Arte, escrito por Ricardo Wagner apresenta as fases artísticas da arte nórdica, comentando as características principais de cada estilo, como também traz imagens ilustrando esses estilos. No caso da arte nórdica, essa não se limitou apenas ao campo da pintura, mas expandiu-se e especializou-se nas áreas da escultura, carpintaria, ourivesaria, joalheira, metalurgia e na própria literatura, especialmente de âmbito poético. Nesse ponto a arte viking embora possa causar estranheza por suas formas humanas e animais pouco detalhadas, como vista na arte clássica (greco-romana) ou na arte gótica cristã, entretanto seus motivos geométricos, abstratos, serpentiformes etc., são ricamente detalhados, principalmente no âmbito da carpintaria e da ourivesaria.

O capítulo nos leva a repensar a ideia de que os vikings fossem bárbaros ignorantes que não possuíssem arte ou cultura. De fato, a própria qualidade de sua arte também era uma condição importante para o comércio, pois os centros comerciais escandinavos entre os séculos X e XI foram exportadores de distintos produtos, entre os quais mercadorias de luxo, ricamente adornadas.

Na metade do livro encontram-se os capítulos sobre arqueologia, os quais abordam os estudos vikings e escandinavos a partir da cultura material de seus túmulos, casas, salões e cidades. A arqueologia ainda hoje consiste numa ciência fundamental para se entender vários aspectos da cultura nórdica da Era Viking, principalmente devido à ausência de relatos escritos da época. Neste caso, o capítulo Arqueologia, escrito por Munir Lufte Ayoub apresenta noções teórico-metodológicas sobre essa ciência e sua aplicação no caso escandinavo. O capítulo intitulado Funerais e Crenças, escrito pelo Dr. Hélio Pires, aborda a arqueologia especificamente no estudo dos ritos fúnebres, os quais eram bem diversificados, diferente da imagem icônica popularizada pelas artes de chefes vikings sendo cremados em seus navios.

Acerca dos últimos capítulos os quais abordam temáticas referentes à religião e sua correlação com a guerra, mitologia, ritos, astrologia, astronomia, magia etc., estes nos trazem atualizações sobre o assunto e algumas novidades, especialmente em respeito da abordagem da etnoastronomia, estudo cultural-astronômico que entre suas funções encontra-se a perspectiva de analisar a importância da astronomia nas sociedades e culturas desde os tempos antigos até o presente. Como os astros e fenômenos meteorológicos e espaciais 
influenciavam os costumes, a sociedade, a política, a religião etc. Algo apresentado no capítulo Cosmologia do professor Johnni Langer.

Embora hoje ao se falar nos vikings, dificilmente não tem como desassociá-los do estereótipo do guerreiro bruto que não possuía medo da morte, mas procurava morrer em batalha para ir a Valhala, condição comentada por Pablo Gomes de Miranda no capítulo Religião e Marcialidade, entretanto, a crenças religiosas dos nórdicos não se limitavam apenas ao campo de batalha, os demais capítulos sobre religião nos fornecem outras informações e visões acerca das crenças e ritos destes povos, revelando tratar-se de uma religião que não era dogmática ou coesa, pois em cada região havia práticas ritualísticas próprias, não havia um clero padronizado, nem livros sagrados ou mandamentos. A religião nórdica era um conjunto de crenças diversas pautadas nos ritos, na magia e nos mitos.

O último capítulo não trata propriamente de um estudo sobre poesia nórdica, mas sim da tradução do poema Pórsdrapa (Canção de elogio ao deus Thor), escrito pelo poeta islandês Eilífr Gođrúnarson, no século X, traduzida por Yuri Fabrício Venâncio. Essa consiste na primeira tradução acadêmica deste poema para a língua portuguesa. O interessante desse capítulo é o fato de termos em primeira mão uma fonte literária traduzida diretamente do nórdico antigo, mas também a oportunidade de ver como era a métrica da poesia daquele tempo, pois o estilo nórdico foi peculiar em suas características, variando em relação a outras regiões do período. Inclusive a poesia nórdica era conhecida por seu grande uso de metáforas (kenningar), muitas referentes a temas da mitologia.

À guisa de conclusão, o livro além de abordar os assuntos comentados, nos fornece uma vasta e atualizada bibliografia apresentada em notas de rodapé ou no final dos capítulos. Por mais que nem em todos os capítulos haja imagens, a obra em si conta com a reprodução de fotografias, pinturas, mapas, gráficos etc. Embora algumas imagens tenham ficado em pequena resolução, dificultando sua visualização. Entretanto, Desvendando os vikings como o título sugere, realmente poderá contribuir para os leitores que queiram seguir os caminhos desses povos que entre os séculos VIII e XI realizaram expedições terrestres e marítimas por três continentes em plena Alta Idade Média. E no caso o acesso a essa obra é fácil e gratuito, pois o livro pode ser baixado no Academia.edu ${ }^{688}$.

688 http://neve2012.blogspot.com.br/2016/11/lancamento-desvendando-os-vikings.html. 